\title{
Assessing the Learning Style of Medical Students in Shahid Beheshti University of Medical Sciences by using VARK Approach
}

\author{
Lida Shams \\ Shahid Beheshti University of Medical Sciences \\ Shahram Yazdani \\ Shahid Beheshti University of Medical Sciences \\ Taha Nasiri \\ Baqiyatallah University of Medical Sciences \\ Jamil Sadeghifar \\ Medical University of Ilam \\ Sara Shahbazi ( $\nabla$ sara.shahbazi@sbmu.ac.ir) \\ Shahrekord University of Medical Sciences
}

\section{Research Article}

Keywords: Learning, Learning styles, Medical students, VARK approach

Posted Date: May 17th, 2021

DOI: https://doi.org/10.21203/rs.3.rs-513470/v1

License: @ (1) This work is licensed under a Creative Commons Attribution 4.0 International License. Read Full License 


\section{Abstract}

Background Extensive factors affect students' learning such as their learning style, the identification of which is considered as important in solving the problems and shortcomings of educational system in the current situation. The present study aimed to determine the learning style of first-year medical students in the Shahid Beheshti University of Medical Sciences in 2018.

Methods In the present descriptive and analytical study, 111 first-year medical students at the university were included through census method. The data were collected by using VARK learning style standard questionnaire and analyzed using SPSS16 software based on the questionnaire guide.

Results Most students had a multi-modal learning style (52\%) although no significant difference was observed between preferring single- and multi-model styles. Among the multi-modal learning styles, bi-modal style was more applied by subjects $(21.62 \%)$. In addition, aural and visual learning styles were determined as the most $(20,37.74 \%)$ and least $(8,15.09 \%)$ frequent styles preferred by students, respectively.

Conclusion Due to the preference of most students to use multimodal styles, medical instructors should highlight the diversity of learners' learning styles and select appropriate methods for students' learning.

\section{Background}

Learning is considered as the process of relatively sustained changes in individuals' potential behavior through experience. In fact, learning is a process and each process is affected by some factors and variables [1]. Thus, many factors influence students' learning such as learning style, the recognition of which is important for solving the problems and shortcomings of educational system in the current situation [2].

Learning style is a process through which an individual understands and retains information, and consequently acquires knowledge and skills. Additionally, it is the preferred style of thinking, processing, and perceiving information, upon which individuals receive information and through which they learn and solve problems [3].

The difference in individuals' learning style may be considered as one of the reasons for the failure of some students to learn well in spite of having the best instructors [4]. Indeed, they get and process information through various methods such as seeing and hearing, reflection and action, thinking, analysis, and imagination depending on their individual traits [5].

Instructors should know that students utilize different learning styles for various reasons, which means that their learning styles change depending on the variations in the learning environment, subjects, and training methods [6].

The issue of learning style is complex and more than 70 different models have been introduced for determining the styles based on the recent studies. The models provide various hypotheses and focus on the different aspects of learner [7]. An individual learning style specifies how new information is processed, internalized, and retained [8]. Bertolami proposed the mismatch between the learning content and teaching approach as one of the main factors for frustration with curriculum among the students [9].

Tailoring and updating the teaching approaches and assessing their effectiveness are considered as essential for improving the motivation and performance of students, and responding their various preferred learning styles [10, 11].

According to Vark, individuals acquire environmental knowledge through four sensory channels of visual, aural, read/write, and Kinaesthetic [12]. In other words, students learn by experiencing, visualizing, thinking, and acting in the education process [13]. This approach is based on three principles, the first of which expresses that everyone can learn academic issues but has his/her specific style and the second refers to an increase in individuals' motivation for learning when their learning styles are highlighted. Based on the third principle, educational content is best learned by utilizing senses and various perceptions [6].

Many literatures confirmed the awareness of learning styles as a small part of the learning process [14]. Identifying students' preferred learning style helps significantly to overcome the tendency of many instructors to behave similarly towards all students [15]. In practice, instructors can train more students because of creating a better fit between them with the learning styles of learner [10, 16-24].

Students acquire and process information through different methods such as seeing and hearing, reflection and action, thinking, analysis, and imagination depending on their individual characteristics [25]. Given that students having various behavioral and 
personality traits exist in different training environments and recognition of their learning styles is considered as an applied guide for instructors to plan and achieve educational objectives, the present study sought to evaluate the learning styles of medical students at the Shahid Beheshti University of Medical Sciences by using VARK approach.

\section{Methods}

The present cross-sectional descriptive study aimed to assess the learning styles of medical students in the Shahid Beheshti University of Medical Sciences. The statistical population of the study included all medical students at the Shahid Beheshti University of Medical Sciences, among whom the first-year ones during 2018-2019 ( $n=111)$ were selected as subjects through purposive sampling method.

In addition, the data were collected by using VARK learning style standard questionnaire. The questionnaire consists of two parts, the first of which contains the questions regarding gender, educational level, and diploma grade point average (GPA), while the second is related to the determination of learning styles among students.

The questions evoke real and understandable scenarios in daily life, which is considered as one of the advantages of using VARK learning styles for recognizing the learning styles. Considering the results related to the study conducted by Fleming in the VARK website, $60 \%$ of respondents confirmed the accuracy of the results obtained from examining their learning styles. However, $5 \%$ referred to the difference between the results and their preferred learning styles and the others did not know much about their preferred learning styles.

Based on the VARK standard questionnaire, learning styles include visual, aural, read/write, and kinaesthetic [25]. The questionnaire consists of 16 questions, each of which puts learner in a learning position. Regarding each question, respondents could select an option presenting the best explanation on their performance in the intended position or more than one item if an option alone does not reflect learners' status. Further, each question did not apply to them can be left unanswered. Furthermore, the content and face validity of the questionnaire was confirmed by medical education experts and the reliability was approved by calculating Cronbach's alpha coefficient in the different studies [26].

Finally, the data were analyzed through the descriptive and inferential statistical tests of chi-square by using SPSS 16 software.

\section{Results}

A total of 111 first-year medical students in Shahid Beheshti University of Medical Sciences participated in the present study. Table 1 summarizes the demographic characteristics of the subjects.

Table 1

Demographic characteristics of the students under study

\begin{tabular}{|llll|}
\hline Variable & & Number & Percentage \\
\hline Gender & Female & 62 & 55.85 \\
\cline { 2 - 4 } & Male & 49 & 44.14 \\
& $19-20$ & 61 & 0.54 \\
\cline { 2 - 4 } & $18-19$ & 8 & 7.20 \\
\hline $17-18$ & 2 & 0.01 \\
\hline $16-17$ & 2 & 0.01 \\
\hline & Unanswered & 38 & 34.23 \\
\hline
\end{tabular}

The results related to learning styles by model and students' preferences are presented in Table 2. Based on the results, most subjects applied multi-modal learning style (52\%) although no significant statistical difference was attained between preferring single-and multimodal ones $(P>0.05)$. 
Table 2

Frequency of subjects by single- and multi-modal learning styles

\begin{tabular}{|c|c|c|c|c|c|}
\hline Percentage & Frequency & $\begin{array}{l}\text { Learning styles by students' preference in each } \\
\text { model }\end{array}$ & Percentage & Frequency & $\begin{array}{l}\text { Learning styles by } \\
\text { model }\end{array}$ \\
\hline 15.09 & 8 & Visual (V) & \multirow[t]{5}{*}{47.75} & \multirow[t]{5}{*}{53} & \multirow[t]{5}{*}{ Single-modal } \\
\hline 37.74 & 20 & Aural (A) & & & \\
\hline 26.42 & 14 & Read/write (R) & & & \\
\hline 20.75 & 11 & Kinesthetic (K) & & & \\
\hline 100 & 53 & Total & & & \\
\hline 20.83 & 5 & $A K$ & \multirow[t]{7}{*}{21.62} & \multirow[t]{7}{*}{24} & \multirow[t]{7}{*}{ Bi-modal } \\
\hline 37.50 & 9 & $A R$ & & & \\
\hline 8.33 & 2 & $R K$ & & & \\
\hline 16.67 & 4 & $V A$ & & & \\
\hline 8.33 & 2 & $V K$ & & & \\
\hline 8.33 & 2 & $V R$ & & & \\
\hline 100 & 24 & Total & & & \\
\hline 40 & 6 & $A R K$ & \multirow[t]{5}{*}{13.51} & \multirow[t]{5}{*}{15} & \multirow[t]{5}{*}{ Tri-modal } \\
\hline 26.67 & 4 & VAK & & & \\
\hline 13.33 & 2 & $V A R$ & & & \\
\hline 20 & 3 & $V R K$ & & & \\
\hline \multirow[t]{2}{*}{100} & 15 & Total & & & \\
\hline & & & 17.21 & 19 & Quad-modal \\
\hline 100 & 111 & & Total & & \\
\hline
\end{tabular}

The results related to the frequency of the students preferring single-modal learning style indicated aural and visual styles as the highest (37.74\%) and least (15.09\%) frequent styles, respectively. Regarding bi-modal style preference, the maximum frequency of students was observed in AR style (37.50\%). Additionally, ARK style (12\%) was more frequent among the students having tri-modal learning style, while the least frequent ones included VAK and VRK ones (both 1.4\%).

Table 3 represents the results of assessing the relationship between demographic characteristics and learning styles. As shown, gender was not related to the styles significantly $(P>0.05)$. Further, both genders applied multi-modal learning style more than the single-model one. Furthermore, male students used multi-modal learning style higher than female ones did although their difference was statistically insignificant. 
Table 3

Relationship between demographic characteristics and learning styles

\begin{tabular}{|c|c|c|c|c|c|c|c|c|c|c|}
\hline \multirow[t]{3}{*}{ Variable } & & \multicolumn{8}{|c|}{ Learning styles } & \multirow{3}{*}{$\begin{array}{l}\text { P- } \\
\text { value }\end{array}$} \\
\hline & & \multicolumn{2}{|c|}{ Single-modal } & \multicolumn{2}{|l|}{ Bi-modal } & \multicolumn{2}{|c|}{ Tri-modal } & \multicolumn{2}{|c|}{ Quad-modal } & \\
\hline & & Number & Percentage & Number & Percentage & Number & Percentage & Number & Percentage & \\
\hline \multirow[t]{2}{*}{ Gender } & Female & 22 & 44.89 & 13 & 26.53 & 8 & 16.32 & 6 & 12.24 & \multirow[t]{2}{*}{0.971} \\
\hline & Male & 30 & 48.38 & 15 & 24.19 & 6 & 9.67 & 11 & 17.74 & \\
\hline \multirow{4}{*}{$\begin{array}{l}\text { Diploma } \\
\text { GPA }\end{array}$} & $16-17$ & 0 & 0 & 0 & 0 & 1 & 0.9 & 1 & 0.9 & \multirow[t]{4}{*}{0.985} \\
\hline & $17-18$ & 0 & 0 & 1 & 0.9 & 1 & 0.9 & 0 & 0 & \\
\hline & $18-19$ & 4 & 3.60 & 2 & 1.80 & 2 & 1.80 & 0 & 0 & \\
\hline & $19-20$ & 29 & 26.12 & 16 & 14.41 & 5 & 4.50 & 11 & 9.90 & \\
\hline
\end{tabular}

Finally, no statistically significant relationship was obtained between diploma GPA and learning styles.

\section{Discussion}

In the present study, most students had multi-modal learning style, which is consistent with the results of some research [26-32]. It seems that humans tend to utilize their maximum capabilities for learning further and more perfectly. In other words, the use of various learning styles covers the learning objectives more completely.

The results of the present study are in agreement with those obtained by other researchers the target population of which was not only medical students (33-34).

However, they are not in line with those of some studies focused on examining the learning style of medical students (35-36). Given that teaching and learning are based on the context, some differences can be expected in the learning styles in the learning positions of other countries by considering cultural, social, and economic conditions, personality traits, and available learning infrastructures.

Various studies have been conducted on the learning style of other medical sciences students, in some of which the results related to medical students were combined with others and not analyzed separately, which are inconsistent with those obtained in the present one (37-39). Fleming pointed out in the VARK website that only $36 \%$ of individuals applied single-modal learning styles, while the most (64\%) had multi-modal ones [25].

Based on the results of the present study, most students utilized bi-modal learning style (21.62\%) among multi-modal ones, which is in agreement with those obtained by some researchers [27, 31-33, 36, 37, 39]. However, it is not in line with those of Farkas et al. [30] and Peyman et al. [33] which indicated preferring quad-modal style (VARK) by students. Ilpour reported tri-modal style as the dominant multimodal ones among students. As already mentioned, learning position and its effect on teaching and learning can likely be effective on the results generally.

In the present study, $48 \%$ of students preferred single-modal learning style (visual, aural, read/write, or kinesthetic) during receiving information, among whom $37.74 \%$ learned through hearing and paid more attention to teachers' words, so-called aural learning style students. In addition, individuals with aural learning style can memorize information through reading aloud, especially when learning new thing [40-42]. Further, $26.02 \%$ of subjects preferred to gain information by applying printed writings, reading, and writing, read/write learning style students, one of the main traits of whom includes better learning through taking notes from lectures and reading the notes. Furthermore, $20.75 \%$ of individuals, kinesthetic learning style ones, preferred a combination of different senses (touching, hearing, smelling, tasting, and seeing), who learn more through experiencing and acting. Finally, $15.09 \%$ had visual style and preferred to acquire information by using figures, charts, and flowcharts. They can draw figure and chart during explaining issues and concepts for others. The results of the previous studies demonstrated that the students preferring visual style are often known as creative and highly imaginative [40]. 
Additionally, aural learning style was reported as the first priority preferred by students in some studies [26, 37, 43-45], which is in line with the results of the present study. Further, Salimi et al. [46] referred to the preference of aural style only among females. However, some researchers reported the priority of visual [47], kinesthetic [28, 30, 31, 49], and read/write style [48].

Due to the difference in the results of various studies, as well as observing multi-modal styles in most individuals, academic instructor should consider this point and utilize diverse teaching approaches to enhance learning.

Based on the results of the present study, most of the subjects having multi-modal learning style applied bi-modal one. Among bi- and tri-modal ones, AR and ARK styles were more preferred by students, respectively. Prithishkumar and Micheal [49] found the preference of first-year medical students in India to use AK and ARK styles among bi- and tri-modal styles. The issue can be related to the fact that subjects preferred to use kinesthetic learning style, and aural style was referred as the first priority in the study. Therefore, aural style was dominant in both single- and multi-modal styles and was utilized by a larger percentage of the students under study.

Finally, diploma GPA and gender were not related to learning style, which is consistent with the results of some researchers which reflected an insignificant relationship between gender and learning style [27, 28, 30, 32, 43, 47]. Accordingly, no relationship is observed between gender and preferred learning styles.

The limitations of the present study are provided as follows. The questionnaire was completed only based on the individual perceptions and could not measure interfering factors such as socio-economic status, race, and culture, similar to the other research using the tool. Additionally, the study was conducted only among first-year medical students who were highly affected by university entrance exam, known as Konkour, which may influence their preference to utilize the learning styles.

\section{Conclusion}

Due to the difference in students' learning styles, matching teaching approaches with the styles is considered as one of the effective methods on deep and sustainable learning. Identifying students' learning styles can result in developing appropriate educational strategies, along with extending proper educational approaches and creating opportunities for instructors [15, 50]. Based on the results of the studies in the education field, most students learn more effectively when instructor provides a combination of visual, aural, $\mathrm{read} / \mathrm{write}$, and kinesthetic activities.

\section{Abbreviations}

VARK: Visual, Aural, Read/write, and Kinesthetic.

\section{Declarations}

\section{Ethics approval and consent to participate}

The present article was extracted from a master's thesis in medical education at Shahid Beheshti University of Medical Sciences with the ethics code No. IR.SBMU.RETECH.REC.1396.952.

All methods were carried out in accordance with relevant guidelines and regulations and all experimental protocols were approved by ethics committee of Shahid Beheshti University of Medical Sciences in the ethics subsection of declaration. Informed consent was obtained from all subjects involved in his study.

\section{Consent for publication}

All authors agree to publish the article.

\section{Availability of data and materials}

The datasets used and analyzed during the current study are available from the corresponding author on reasonable request.

\section{Competing interests}

The authors declare that they have no competing interests. 


\section{Funding}

Not applicable.

\section{Authors' contributions}

LS and SY conceptualized the study, developed the proposal, coordinated the project. LSH and TN completed initial data entry and analysis, and wrote the report. LS and SYJ and JS conducted the statistical analyses. LSH, TN and SSH assisted in writing and editing the final Manuscript. SY and LSH participated in overall supervision of the project and revision of the report. All authors read and approved the final manuscript.

\section{Acknowledgements}

The author would thank all of the students and instructors co-operating in the study.

\section{References}

1. Najafipour S, Mosalinejad L, Najafipour S. Training for Learning and Learning for Training. 1 ed: Omid Publication; 2009

2. Azizi F, Khanzadeh A, Hosseini M. A survey on leaning styles of medical students (Based on Kolb theory) in Qazvin. Iranian Journal of Medical Education. 2002;2:16-.

3. Fleming N, Mills C. VARK: A Guide to Learning Styles. 2001. Last accessed on. 2004;

4. McLeod M, editor They all Learn the Same... Don't They?: An Evaluation of the Learning Style Preferences of the NZ Dairy Industry. International Teamwork in Agricultural and Extension Education Conference Proceedings;

5. Mills DW. Applying what we know: Student learning styles. Retrieved April. 2002;7:2009.

6. A S. Educational Psychology. Tehran. Agah Publications. 2006.

7. Coffield F, Moseley D, Hall E, Ecclestone K. Learning styles and pedagogy in post-16 learning: A systematic and critical review. Learning and Skills Research Centre London;

8. Fang AL. Utilization of learning styles in dental curriculum development. The New York state dental journal. 2002;68(8):34-8.

9. Bertolami CN. Rationalizing the dental curriculum in light of current disease prevalence and patient demand for treatment: form vs. content. Journal of dental education. 2001;65(8):725-35; discussion 36-43.

10. Miller P. Learning Styles: The Multimedia of the Mind. Research Report.

11. Felder RM, Brent R. Understanding student differences. Journal of engineering education. 2005;94(1):57-72.

12. Alkhasawneh IM, Mrayyan MT, Docherty C, Alashram S, Yousef HY. Problem-based learning (PBL): assessing students' learning preferences using VARK. Nurse education today. 2008;28(5):572-9.

13. Boyle EA, Duffy T, Dunleavy K. Learning styles and academic outcome: The validity and utility of Vermunt's Inventory of Learning Styles in a British higher education setting. British journal of educational psychology. 2003;73(2):267-90.

14. E D, M V. Learning style awareness: Why would it work? Paper presented at the Proceedings of the Eighth Annual European Learning Styles Information Network Conference. 2003:139-50 Hull, UK: University of Hull. .

15. Fleming N. I'm different; not dumb. Modes of presentation (VARK) in the tertiary classroom. In: Research and Development in Higher Education, edited by Zelmer A. Proceedings of the 1995 Annual Conference of the Higher Education and Research Development Society of Australasia. 1995;18:308-13.

16. Armstrong E, Parsa-Parsi R. How can physicians' learning styles drive educational planning? Academic Medicine. 2005;80(7):680-4.

17. Collins J. Education techniques for lifelong learning - principles of adult learning. Radiographics. 2004;24(5):1483-9.

18. Forrest S. Learning and teaching: the reciprocal link. The Journal of Continuing Education in Nursing. 2004;35(3):74.

19. Laight DW. Attitudes to concept maps as a teaching/learning activity in undergraduate health professional education: influence of preferred learning style. Medical Teacher. 2004;26(3):229-33.

20. Lang H, Stinson M, Kavanagh F, Liu Y, Basile M. Learning styles of deaf college students and instructors' teaching emphases. Journal of deaf studies and deaf education. 1999;4(1):16-27.

21. Pillemer D, Wink P, DiDonato T, Sanborn R. Gender differences in autobiographical memory styles of older adults. Memory. 2003;11(6):525-32. 
22. Sandmire DA, Boyce PF. Pairing of opposite learning styles among allied health students: Effects on collaborative performance. Journal of Allied Health. 2004;33(2):156-63.

23. Veenman MVJ, Prins FJ, Verheij J. Learning styles: Self-reports versus thinking-aloud measures. British Journal of Educational Psychology. 2003;73(3):357-72.

24. Bergman LG, Fors UGH. Computer-aided DSM-IV-diagnostics-acceptance, use and perceived usefulness in relation to users' learning styles. BMC Medical Informatics and Decision Making. 2005;5(1):1.

25. Fleming N, Mills C. VARK: A Guide to Learning Styles. 2001. Last accessed on. 2004;30.

26. Zeraati A HH, Shojaian R. Learning styles of medical and midwifery students in Mashhad University of Medical Sciences. Journal of medical education. 2008;12(1,2).

27. Prithishkumar IJ MS. Understanding your student: using the VARK model. Journal of postgraduate medicine $2014 ; ; 60(2): 183$

28. Baykan Z NM. Learning styles of first-year medical students attending Erciyes University in Kayseri, Turkey. Advances in physiology education. 2007 31(2):158-60.

29. OJEH N S-GN, GAUR U, UDUPA A, MAJUMDER MA. . Learning style preferences: A study of pre-clinical medical students in Barbados. Journal of advances in medical education \& professionalism. 2017 5(4):185.

30. Farkas GJ ME, Marone JR. . Learning style versus time spent studying and career choice: Which is associated with success in a combined undergraduate anatomy and physiology course?. Anatomical sciences education. 2016 Mar;9(2):121-31.

31. Kharb P SP, Jindal M, Singh V. . The learning styles and the preferred teaching-learning strategies of first year medical students.. ;. Journal of clinical and diagnostic research: JCDR. 2013Jun;7(6):1089.

32. Shete AN GK. Learning Style Preferences of First Year Medical Students-A Single Institute Study. Journal of Research in Medical Education \& Ethics. 2017(7(1):13-6).

33. Peyman H SJ, Khajavikhan J, Yasemi M, Rasool M, Yaghoubi YM, Nahal MM, Karim H. Using VARK approach for assessing preferred learning styles of first year medical sciences students: a survey from Iran. Journal of clinical and diagnostic research: JCDR. 2014 Aug;8(8):GC01.

34. Salimi M, Sadeghifar J, Peyman H, Shams L, Jandagheian M, Khosravi A, et al. visual, aural, read/write, and kinesthetic learning styles preferences in students of isfahan university of medical sciences, Iran. 2012.

35. Paiboonsithiwong S, Kunanitthaworn N, Songtrijuck N, Wongpakaran N, Wongpakaran T. Learning styles, academic achievement, and mental health problems among medical students in Thailand. Journal of educational evaluation for health professions. 2016;13.

36. Sarabi-Asiabar A JM, Sadeghifar J, Tofighi S, Zaboli R, Peyman H, Salimi M, Shams L. The relationship between learning style preferences and gender, educational major and status in first year medical students: a survey study from iran. Iranian Red Crescent Medical Journal. 2015 Jan;17(1).

37. Mehdipour M., Mortazavi H., Yazdani J., Dastan Pour S., Namdari M., Moradi M. Learning styles of dental students at Shahid Beheshti University of Medical Sciences using VARK questionnaire. Iranian Journal of Medical education, 2018; 18: 176-182.

38. Azadmanesh Y., Azimian J., Zeighami R., Jahani-Hashem H. Correlation between learning styles and the characteristics of nursing and midwifery students in Qazvin University of Medical Sciences using the VARK model.

39. Moghadam M., Behnam Moghadam A., Rostaminejad A., Salehian T. A study on the learning styles of nursing and midwifery students in Yasuj according to the VARK model (2013).

40. Othmana N, Amiruddinb MH. Different Perspectives of Learning Styles from VARK Model. International Conference on Learner Diversity. 2010:652-60.

41. Drago WA, Wagner RJ. Vark preferred learning styles and online education. Management Research News. 2004;27(7):1-13.

42. Murphy RJ, Gray SA, Straja SR, Bogert MC. Student learning preferences and teaching implications. Journal of dental education. 2004;68(8):859-66.

43. Javadinia A., Sharifzade G., Abedini M., Khalesi M., Erfaniyan M. Learning styles of medical students in Birjand University of Medical Sciences according to VARK model. Iranian Journal of Medical Education, 2012; 11 (6): 584-589.

44. Mohammadi Y., Kazemi S., Hajabadi M., Raisson M. The relationship between physiological learning styles, creativity, and academic achievement among students at Birjand University of Medical Sciences during the academic year 2013-2014.

45. Zamani N, Kaboodi A. Evaluation of the VARK Model Learning Styles Selection in Medical Students. Health Research. 2017;2(2):109-15. 
46. Salimi M., Sadeghifar J., Peyman H., Shams L., Jandagheian M., Khosravi A., Khajavikhan J., Abbasi M. Visual, aural, read/write, and kinesthetic learning styles preferences in students of Isfahan University of Medical Sciences. Scientific Research Journal of Health System Research, 2013b; 8 (7): 1216-1224.

47. Amini N., Zamani B.E., Abedini Y. Medical students' learning styles. Iranian Journal of Medical Sciences. $2010 ; 10$ (2): $141-147$.

48. OJEH N S-GN, GAUR U, UDUPA A, MAJUMDER MA. . Learning style preferences: A study of pre-clinical medical students in Barbados. Journal of advances in medical education \& professionalism. 2017 5(4):185.

49. Prithishkumar IJ MS. Understanding your student: using the VARK model. Journal of postgraduate medicine $2014 ; .60(2): 183$.

50. Tanner K, Allen D. Approaches to biology teaching and learning: learning styles and the problem of instructional selectionengaging all students in science courses. Cell Biology Education. 2004;3(4):197-201. 